\title{
Geometry in Outcomes-Based Education: Project-Based Versus Conventional Learning
}

\author{
Nafaa Chbili \\ Department of Mathematical Sciences, United Arab Emirates University, 15551 Al Ain, UAE \\ * E-mail of the corresponding author: nafaachbili@uaeu.ac.ae
}

\begin{abstract}
The unprecedented Covid-19 lockdown brought additional challenges to education systems worldwide. This led to increasing discussions about teaching methods. Educators are required to adapt their teaching methodologies and strategies to respond to students' need without compromising quality requirements. In this context, projectbased learning seems to gain more advocates and gather momentum as this methodology is apparently more appropriate for distance learning. In this paper, we describe how project-based learning had been implemented as a remedial action to certain deficiencies in students' mastery of a learning outcome in an axiomatic geometry undergraduate course. For this purpose, a study had been carried to measure the effectiveness of PBL in comparison to conventional learning. We present some results of course learning outcomes assessments that show an improvement in the level of attainment of a specific course learning outcome as a consequence of the change of instructional methodology from traditional to project-based learning
\end{abstract}

Keywords: Course learning outcomes, Project-based learning (PBL), Geometry

DOI: $10.7176 / \mathrm{JEP} / 11-35-03$

Publication date: December $31^{\text {st }} 2020$

\section{Introduction}

Project-based learning is a student-centred instructional methodology where students advance or gain new knowledge through teamwork and problem-solving by applying scientific methods. The process is based on three constructivist principles: learning is context-specific, learners are involved actively in the learning process and they achieve their goals through social interactions and the sharing of knowledge and understanding (Cocco, 2006). This approach, which emerged within the past few decades, encompasses several levels of cognitive complexity and promotes the synthesis of different aspects of learning.

Many authors have highlighted the effectiveness of this learning method which is recognized as one of the best approaches for developing general skills such as independent learning, problem solving, creativity and teamwork (Barak, 2012). It is also argued that working on projects helps develop capacity of students to plan and manage own learning. Furthermore, several studies have emphasized that this practice improves students' learning and that it has positive effects on students' attitudes towards technology (Mioduser \& Betzer, 2007), science (Catherine \& Barry, 2008) and mathematics (Kuo-Hung, Chi-Cheng \& Shi-Jer 2013).

In higher education, the extent to which PBL is used varies from one subject to another. According to (Kokotsaki, Menzies \& Wiggins, 2016), most of the studies about the effectiveness of PBL in undergraduate curriculum focuses on engineering education. On the other hand, several studies showed that pre-service teachers can gain many benefits through the implementation of PBL. In particular, they become better problem-solvers (Mettas \& Constantinou, 2008).

In mathematics higher education, the implementation of PBL remains limited. Indeed, there are many restrictions to the use of this approach in undergraduate mathematics education. This is due to the abstract nature of the subject, in addition to number of other interrelated factors. In literature, there are a few studies about PBL in undergraduate mathematics education. For instance, two cases of university PBL in mathematics; one in pure mathematics and the other in applied mathematics are presented in (Dahl, 2018). Another interesting study examined the effectiveness of PBL in teaching ordinary differential equations, (Santos, Xavier \& Santos 2020). We believe that there is room for further investigating the effectiveness of this instructional methodology in different mathematics undergraduate subjects. Especially, its effect on pre-service mathematics teachers needs to be further studied.

Outcomes-Based Education is an educational model in which the curriculum, pedagogy and assessment are all focused on student learning outcomes, (Driscoll \& Wood, 2007). This model bases each part of the curriculum around learning outcomes. Each student is supposed to attain the pre-defined list of intended outcomes by the end of his/her education experience. One of the advantages of this approach is that it provides different parties with a clear understanding of the education process, its objectives and its goals. It guides learners focus on clearly defined outcomes and it helps instructors to design appropriate assessments to measure students' achievements. Thanks to such evidence-based evaluation, new strategies for teaching and learning are developed and remedial actions can be taken if necessary. In outcomes-based education model, each component of the curriculum has a list of course learning outcomes (CLOs). These outcomes are aligned with the program learning outcomes which are in turn 
aligned with the institutional learning outcomes. Notice here that by a course learning outcome we mean a formal statement of exactly what students should be able to do after completing the course or at any specific time during the course. Our main objective in this paper is to study how student's attainment of CLOs changes with the change of teaching method from conventional teaching to project-based learning.

The study we present in this paper had been carried in an undergraduate geometry course. PBL was implemented as a remedial action taken to improve students' attainment level of a certain CLO. The course covers topics in Euclidean and hyperbolic geometry. It has a list of six intended learning outcomes. At the end of each semester, the level of attainment of each outcome is measured through different assessment tools. After a first offering of this geometry course, we noticed a deficiency in the students' mastery of CLO1. The statement of this outcome reads as follows "construct geometric figures using straightedge and compass". This outcome is related to a number of fundamental skills that students in mathematics, pre-service mathematics teachers, and engineering students are supposed to master. A first set of remedial actions had been implemented in the subsequent course offering. These actions consisted mainly in allocating more in class time to discuss certain material related to this outcome and providing students with more examples of constructions. However, no significant improvement in students' performance had been observed. Thus, a decision to change the teaching method had been considered. As the main stakeholders, students had been consulted and surveyed in this regard. Different instructional approaches had been investigated and discussed, such as blended learning and project-based learning. Students' feedback showed more interest in the implementation of project-based learning. The paper presents the results obtained in the attainment of the learning outcome mentioned above after such change in the learning methodology.

\section{The Method}

\subsection{The course}

Geometry is a fundamental branch of mathematics with important applications in many fields of science and engineering. Geometry is taught almost at all levels of curricula, from primary schools where basic shapes and elementary rules of computing areas are introduced to graduate level where the study of the shape of the universe is a cutting-edge research topic. Generally, geometry is offered at university undergraduate level to students in different colleges, including science and engineering. This course is also of fundamental importance to pre-service teachers. According to (Jones, 2002) "geometry contributes to helping students develop the skills of visualization, critical thinking, intuition, perspective, problem-solving, conjecturing, deductive reasoning, logical argument and proof'. Unlike other branches of mathematics such as calculus and linear algebra, geometry is not computational. Consequently, teaching geometry solving techniques to students is generally a very challenging task. Indeed, there is no agreement among educators about the most effective teaching approach and considerable amount of research work in mathematics education has been done to address issues related to teaching and learning of geometry (Clements, 2002).

\subsection{The outcomes}

The geometry course considered in this paper has a list of six intended learning outcomes. All of these outcomes are assigned the same weight. We are concerned here with outcome 1 which can be stated as "construct geometric figures using straightedge and compass". Note that construction problems are of central importance in Euclidean geometry, "Problems of geometric constructions using ruler and compass, or only ruler, form a very special class of problems which, in order to be solved, require not only a very good knowledge of basic results in geometry but also special skills and cleverness" (Berinde, 2002).

\subsection{The assessment}

Several assessment tools are used in this course. Those related to outcome 1 involve both direct and indirect tools. The outcome attainment level is defined as the percentage of students who scored $70 \%$ or higher. In the context of our study, the outcome is considered as attained if the calculated attainment level is equal to or greater than a predefined attainment target, which is set to $70 \%$. Equivalently, $70 \%$ of students should score, each, an average of at least $70 \%$ in the different assessment tools associated with the outcome. For the study of the attainment level of this specific outcome, we used two direct assessment tools including the final exam. These two assessments are accounted $15 \%$ of student's final grade in the course. Another indirect assessment tool is also considered. A student survey is conducted at the end of the semester. In this survey, students are asked: how well they feel that they have mastered the expected learning outcomes of the course.

\subsection{The population}

The population involved in this study are second-year undergraduate students enrolled in a higher education institution in the United Arab Emirates. These are not only mathematics major students, but also students enrolled in other programs such as engineering and mathematics education (future mathematics schoolteachers). These students attended the one-semester geometry course described above and covering topics in both Euclidean and 
hyperbolic geometry. For the purpose of our study, students are split into two groups.

\subsubsection{Experimental group}

This section of 20 students learned the material related to geometric construction through project-based learning. Students worked in small teams on some projects suggested by the instructor. A short session was organized to provide students with project guidelines, explain what is required from them and clarify the evaluation process. The project consisted of two parts. A first part where students were asked to make some basic constructions in planar Euclidean geometry. These problems ranged from elementary ones to advanced multi-step constructions. For each problem, students should list the construction steps, illustrate that by a neat figure, and then provide a complete rigorous proof. Students were authorized to draw the figures by hand or using any software. The second part of the project consisted of the creation of a new original design using only compass and straightedge. This design can be of artistic, engineering or industrial type. Each group of students should submit a written report and make a short presentation at the end of the semester.

2.4.2 Control group

The control group was made up of 18 students enrolled in the same geometry course as the experimental group. The course content related to the above-mentioned outcome was delivered to students of this group by means of conventional teaching methods. This included smartboard lectures and power-point presentations by the instructor. In addition, students attended a problem-solving session where examples of constructions using compass and straightedge were discussed.

\section{Results}

Prior to discussing our findings in this study, it is noteworthy to mention that while the learning approach for the course content related to outcome 1 was not the same for the control and experimental groups, the rest of the course content was introduced using the same methods. More precisely, power-point presentations, technology tools and several features of traditional teaching were used. Students had been assessed in the final exam in addition to one quiz by means of written questions of exactly same type and level for both groups. In addition, a survey had been conducted in the last week of the semester. Statistics show that the attainment level of outcome 1 was clearly higher in the experimental group. Indeed, in this group, $75 \%$ of students scored, each, higher than $70 \%$. Whereas, in the controlled group only $66 \%$ of students scored higher than $70 \%$. In other words, for the experimental group the outcome is considered as attained, while it is not the case for the control group.

On the other hand, the attainment levels of the other five outcomes of the course are comparable. The average of attainment level in the experimental group is $73 \%$. It is about $71 \%$ for the control group. This proves that with the same means of instruction, attainment levels are almost equal for both groups. This also gives an evidence that the implementation of PBL worked effectively as a remedial action to the deficiency in students' mastery of outcome 1.

The analysis of the results of student survey reinforces our conclusion above. As mentioned earlier, students in both groups were surveyed about their level of mastery of the six outcomes. Each student had to answer a questionnaire where he/she self-evaluates his/her level of mastering of each outcome. The survey was conducted before taking any written assessment addressing outcome 1 . Survey results confirmed that students in experimental group are more confident toward the achievement of outcome 1 than those in the control group. Students' responses to the same question about the other five outcomes show no significant difference between the two groups.

\section{Conclusion}

As had been stated above, the study presented in this paper was aimed to evaluate the effectiveness of implementing project-based learning method as a remedial measure for the deficiencies in student's mastery of a learning outcome in a university undergraduate geometry course.

Direct assessments proved that students who used project-based learning, achieved higher than those who had been taught by the traditional means. For the other outcomes, no significant difference between the achievements of the two groups was noticed. Similarly, indirect assessments carried through student surveys showed that students in the experimental group feel more prepared for the exams and more confident in mastering the considered outcome. In general, students' feedback, both in person and in the course evaluations, was positive.

The study proved an improvement in learning process by applying PBL. However, it should be noted that the method was applied only for some specific course outcome, and that there is no evidence that similar results can be obtained for the other outcomes. Additionally, it is worth mentioning that students who participated in this study are from different colleges and that we have initial observations about the level of students' response to this change in the teaching methodology, considering their academic background. We believe that further investigation is required in order to confirm these initial observations. 


\section{References}

Cocco, S. (2006). "Student leadership development: The contribution of project-based learning" (Unpublished Master thesis). Royal Roads University, Victoria, BC, Canada

Barak, M. (2012). "From 'doing' to 'doing with learning': Reflection on an effort to promote self-regulated learning in technological projects in high school", European Journal of Engineering Education, 37(1), 105-116

Mioduser, D., and Betzer, N. (2007). "The contribution of project-based-learning to high-achievers' acquisition of technological knowledge and skills", International Journal of Technology and Design Education, 18, 59-77

Catherine, M., and Barry, J. F. (2008). "Learning environment and attitudes associated with an innovative science course designed for prospective elementary teachers", International Journal of Science and Mathematics Education, 6(1), 163-190

Kuo-Hung T., Chi-Cheng C., Shi-Jer L., and Wen-Ping C. (2013). "Attitudes towards science, technology, engineering and mathematics (STEM) in a project-based learning (PjBL) environment", International Journal of Technology and Design Education, 23(1), 87-102

Kokotsaki, D., Menzies, V., and Wiggins, A. (2016). "Project-based learning: A review of the literature", Improving Schools, 19(3), 267-277

Mettas, A., and Constantinou, C. P., (2008). "The technology fair: A project-based learning approach for enhancing problem solving skills and interest in design and technology education", International Journal of Technology and Design Education, 18, 79-100

Dahl, B. (2018). "What is the problem in problem-based learning in higher education mathematics?" European Journal of Engineering Education, 43(1), 112-125

Santos, L., Xavier, P., and Santos, J., (2020). "Teaching of Ordinary Differential Equations Using the Assumptions of the PBL Method", International Journal of Engineering Pedagogy. 10(3), 7-18

Driscoll, A., and Wood, S., (2007). "Developing Outcomes-Based Assessment for Learner-Centred Education: A Faculty Introduction", Sterling, VA: Stylus

Jones, K. (2002)."Issues in the Teaching and Learning of Geometry", In: Linda Haggarty (Ed), Aspects of Teaching Secondary Mathematics: perspectives on practice. London: Routledge Falmer. Chapter 8, 121-139

Clements. D. (2001). "Teaching and Learning Geometry", In J. Kilparick (Ed) Research Companion to the NCTM Standards for Mathematics. Reston, VA: NCTM

Berinde V. (2004). "A Geometric Construction Using Ruler and Compass", In: Exploring, Investigating and Discovering in Mathematics. Birkhäuser, Basel 